\title{
Stemming Bahasa Tetun Menggunakan Pendekatan Rule Based
}

\author{
Anita Guterres \\ Magister Teknologi Infomasi \\ Sekolah Tinggi Teknik Surabaya \\ anitaguterres85@gmail.com
}

\author{
Gunawan \\ Magister Teknologi Informasi \\ Sekolah Tinggi Teknik Surabaya \\ gunawan@stts.edu
}

\author{
Joan Santoso \\ Magister Teknologi Infomasi \\ Sekolah Tinggi Teknik Surabaya \\ joan@stts.edu
}

\begin{abstract}
Abstrak - Stemming adalah proses yang sangat penting untuk mencari kata dasar dari sebuah kata derivatif. Inti dari proses stemming adalah menghilangkan imbuhan pada suatu kata. Stemming sangat dibutuhkan untuk proses information retrieval system. Algoritma pada proses stemming bisa berbeda-beda pada setiap bahasa di berbeda negara. Data yang digunakan adalah 176 kata dasar dalam bahasa Tetun yang merupakan bahasa asli warga negara Timor Leste. Penelitian ini bertujuan untuk merancang algoritma baru yang tepat untuk stemming bahasa Tetun. Tahap awal stemming bahasa Tetun adalah proses filterisasi untuk menghilangkan tanda baca, angka, dan kata yang tidak penting. Lalu tahap tokenisasi untuk membuat variabel yang terdiri dari satu kata. Lalu setiap kata melalui proses stemming untuk menghilangkan imbuhan awalan, akhiran, dan konfiks. Analisis dilakukan berdasarkan kasus error stemming seperti overstemming, understemming, unchanged, dan spelling exception. Hasil uji coba yang didapatkan adalah algoritma stemming bahasa Tetun menghasilkan akurasi sebesar $90.52 \%$.
\end{abstract}

Kata Kunci: Bahasa Tetun, Stemmer

\section{LATAR BELAKANG}

Stemming merupakan suatu proses untuk mengubah kata berimbuhan menjadi kata dasar. Pada umumnya bahasa Tetun merupakan bahasa resmi yang digunakan negara Timor Leste menjadi bahasa kerja. Namun bahasa Tetun sendiri ada 2 macam yaitu Tetun Frasa (Tetun Dili) dan Tetun Terik (Suai, Viqueque, dan Belu Nusa Tenggara Timur di Indonesia) yang terletak di perbatasan Indonesia dan Timor Leste. Di Belu, bahasa Tetun digunakan sebagai bahasa sehari hari dan lebih menyerap bahasa Indonesia karena terpisah dari negara Timor Leste setelah merdeka. Sedangkan Tetun Terik di Viqueque dan Suai digunakan sebagai bahasa kerja. Pada Tetun Frasa dan Tetun Terik masih terdapat kata yang belum ditemukan padanannya oleh ahli bahasa Tetun sehingga masih meminjam dari bahasa lain seperti bahasa Portugis dan bahasa Indonesia. Walaupun bahasa Tetun adalah bahasa resmi dan digunakan sebagai bahasa kerja, tetapi masih sulit diterapkan di tempat kerja, sehingga dalam prakteknya masih menggunakan bahasa campuran seperti bahasa Portugis dan bahasa Indonesia, dikarenakan 2 negara tersebut pernah menjajah Timor Leste.

\section{TINJAUAN ALGORITMA STEMMER PADA BAHASA LAIN}

Stemming merupakan suatu proses untuk menemukan kata dasar dari sebuah kata dengan menghilangkan semua imbuhan (affixes) baik yang terdiri dari awalan (prefixes), sisipan (infixes), akhiran (suffixes), dan confixes (kombinasi dari awalan dan akhiran) pada kata turunan. Stemming adalah tools dasar pemprosesan teks yang digunakan untuk text retrieval (Frakes, 1992), mesin penterjemah (Bakar dan Rahman, 2003), meringkas dokuman (Orasan et al., 2004) dan klasifikasi teks (Gaustad ang Bouma, 2002). Berdasarkan asumsi bahwa term yang memiliki akar kata yang sama akan selalu memiliki makna yang sama, stemming digunakan pada information retrieval untuk meningkatkan keakurasian retrieval (perolehan informasi). Selain untuk meningkatkan keakurasian retrieval, stemming yang dilakukan pada proses indexing juga akan mengurangi ukuran dari indeks file [1].

\section{A. Bahasa Indonesia}

Algoritma Nazief dan Adriani Stemmer diciptakan oleh Bobby A. A. Nazief dan Mirna Adriani yang berasal dari Universitas Indonesia pada tahun 1996. Pada sub bab ini akan dijelaskan tentang algoritma dan contoh penggunaanya.

Algoritma ini sangat berhubungan dengan peraturan morfologi bahasa Indonesia dengan mengelompokkan dan meringkas imbuhan-imbuhan yang diperbolehkan. Imbuhan yang dimaksud adalah awalan, akhiran, gabungan antara awalan dengan akhiran, dan sisipan. Algoritma ini memiliki proses recording yang digunakan untuk mengembalikan huruf awal dari kata dasar yang hilang karena proses penghilangan akhiran dari sebuah kata. Algoritma ini juga memiliki kamus data kata dasar yang digunakan pada setiap langkah untuk memeriksa hasil proses stemming untuk mendapat kata dasar yang dicari [2].

1. Akhiran Infleksi (Inflection Suffix)

Akhiran infleksi merupakan akhiran yang tidak mengubah kata dasarnya. Contohnya adalah kata "baca" diberi akhiran "-lah" maka akan membentuk kata "bacalah". Akhiran infleksi terdiri dari dua macam, yaitu:

a. Kata sandang/particles $(\mathrm{P})$ 
Terdiri dari akhiran "-lah" dan "-kah". Contohnya adalah kata "bacalah", "benarkah".

b. Kata ganti milik/Possessive Pronouns (PP)

Terdiri dari akhiran "-ku”, “-mu”, “-nya”. Contohnya adalah kata "ayahku", ayahmu", "ayahnya".

Kata sandang dan kata ganti milik bisa digunakan bersama dalam satu kata. Jika digunakan dalam satu kata maka kata ganti milik akan muncul sebelum kata sandang.

2. Akhiran Derivasi/Derivation Suffix (DS)

Akhiran Derivasi adalah kumpulan akhiran yang bisa digabungkan bersama-sama pada kata dasar. Setiap kata hanya bisa diberi lebih dari satu akhiran derivasi. Contohnya adalah kata "mati" bisa diberi akhiran "-kan" maka akan membentuk kata "matikan". Lalu diberi satu akhiran lagi dengan akhiran "-lah" maka akan membentuk kata "matikanlah".

3. Awalan Derivasi/Derivation Prefix (DP)

Awalan Derivasi adalah kumpulan awalan yang bisa digabungkan bersama-sama pada kata dasar, atau pada kata-kata yang punya maksimal dua awalan. Contohnya adalah kata "indah" bisa diberi awalan "mem-" dan "per" sehingga akan membentuk kata "memperindah".

B. Bahasa India

Pada tahun 2010, Dinesh Kumar dan Pangeran Rana mengembangkan desain dan pengembangan stemmer untuk Punjabi, menggunakan algoritma Brute Force untuk membendung kata Punjabi. Pada tahun 2001, Shambhavi dkk. mengenalkan penganalisis morfologi Kannada. Stemmer untuk bahasa Hindi dikembangkan oleh Ramanathan pada tahun 2004. Dalam penelitian ini, mengubah kata-kata dengan menghapus suffix untuk pencarian informasi. Willet $\mathrm{P}$ mengusulkan algoritma stemming untuk perpustakaan elektronik dan sistem informasi pada tahun 2006. Zahurul MD mengembangkan stemmer untuk bahasa Bengali pada tahun 2009 untuk memeriksa ejaan bahasa Bengali. Affix-exception berbasis Urdu stemmer dikembangkan oleh Qurat-Ul-Ain Akram.

Tipologi morfologi bahasa untuk pencarian informasi ditemukan oleh Pirkola A. Dalam penelitian ini, IRS mengambil informasi berdasarkan tipologi morfologi. Pada tahun 1996, Hull D mengembangkan studi kasus algoritma stemming untuk evaluasi terperinci guna mengevaluasi kinerjanya.

Diusulkan oleh Mudassar untuk menemukan kata Marathi tersembunyi di Knowledge Discovery Database (KDD). Entitas yang diberi nama dalam bahasa Telugu menggunakan fitur yang bergantung pada bahasa dan pendekatan berbasis aturan dikembangkan oleh Sridhar B. Di tahun 2011, Model yang diusulkan menggunakan Named Entity Recognition (NER) untuk membendung kata-kata Telugu. Juhi Ameta memperkenalkan stemmer ringan untuk Gujarati di tahun 2012. Dalam model yang diusulkan ini, algoritma penanda akhiran digunakan untuk membendung kata-kata Tamil ke akar kata-katanya.

Algoritma Maulik digunakan untuk membendung katakata Hindi. Pada tahun 2012 sebuah stemmer iteratif untuk
Bahasa Tamil diusulkan oleh Vivekanandan Ramachandran, dkk [3].

\section{MORFOLOGI BAHASA TETUN}

Bahasa Tetun merupakan bahasa resmi dan sudah tercantum di Konstitusi Negara Timor Leste, untuk digunakan sebagai bahasa kerja. Namun bahasa Tetun sendiri masih ada kata yang belum ditemukan oleh alih bahasa Tetun, sehingga masih ada kata yang meminjam dari bahasa lain seperti bahasa Portugis dan bahasa Indonesia. Timor Leste dipengaruhi oleh beberapa bahasa dikarenakan negara Timor Leste pernah dijajah oleh negara lain, seperti negara Portugal dan Indonesia, sehingga dalam bahasa Tetun sulit ditemukan katakata seperti awalan, akhiran, awalan dan akhiran, sisipan dan reduplikasi, dibandingkan dengan bahasa Indonesia.

Tetun yang digunakan dalam penelitian ini adalah Tetun campuran yaitu Tetun Frasa (Tetun Dili) dan Tetun Terik (Tetun Suai dan Viqueque), dikarenakan terdapat kata-kata yang tidak ada di Tetun Frasa dan begitu juga di Tetun Terik, seperti kata imbuhan awalan, imbuhan akhiran, imbuhan awalan dan akhiran, sisipan, dan kata reduplikasi.

Awalan yang diperbolehkan dalam pembentukan bahasa Tetun adalah sebagai berikut:

1. Aturan awalan (prefiks)

Aturan awalan yang diperbolehkan sebagai berikut:

- Ha - + Tún = Hatún Contoh awalan kata dari Ha- sebagai berikut: Nita tún husi kareta $=$ Nita turun dari mobil Nita hatún husi kareta $=$ Nita diturunkan dari mobil

- $\mathrm{Na}-+$ Kurut $=$ Nakurut Contoh awalan kata dari Na- sebagai berikut: Hau hare hena ne,e kurut tiha ona = Saya lihat kain itu sudah kusut

O nian hena nakurut tiha ona = Kain kamu sudah kusut

- Nak- + Lees = Naklees

Contoh awalan kata dari Nak- sebagai berikut:

Hau lees tiha ona suratahan = Saya sudah merobek kertas

Suratahan naklees tiha ona $=$ kertas sudah dirobek

- Nam- + kari = Namkari

Contoh awalan kata dari Nam- sebagai berikut:

Giterus ba kari aifunan iha Rate = Giterus pergi menabur bunga di makam

Aifuna namkari deit = Menyebar bunga saja

Aturan khusus untuk awalan yang diperbolehkan seperti

Na-, Nak-, Nam-, contoh sebagai berikut:

- Na- digunakan untuk barang yang sudah kusut tapi bisa diperbaiki

Contoh: baju itu sudah kusut

- Nak- digunakan untuk sesuatu yang tidak bisa diperbiki

Contoh: Surat itu sudah disobek oleh adik

- Nam- digunakan untuk sesuatu yang dilakukan masih tertunda

Contoh: nanti kami akan menabur bunga di makam

- Aturan awalan yang tidak diperbolehkan 
Dór, N, Tén

2. Aturan akhiran (sufiks) yang diijinkan

- Halimar + -dór = Halimardór Contoh akhiran kata -Dór adalah sebagai berikut: Nita ema nebe'e halimardór $=$ Nita orang yang suka bercanda

- Tunu $+-n=$ Tunun Contoh akhiran kata - $\mathbf{N}$ adalah sebagai berikut: Hau tunun batar = Saya membakar jagung

- Bosok + tén = Bosoktén Contoh akhiran kata -Tén adalah sebagai berikut: Mane ne'e bosoktén = Pria itu pembohong

- Akhiran kata yang tidak diijinkan $\mathrm{Ha}, \mathrm{Na}, \mathrm{Nak}$, Nam

3. Aturan awalan dan akhiran (konfiks) Gabungan kata awalan, tengah, dan akhiran untuk membentuk kata baru yang berhubungan dengan kata yang pertama

- $\mathrm{Ma}+$ husu + k = Mahusuk

Contoh kata awalan dan akhiran sebagai berikut:

Hau sei husu Maria = Saya akan tanyakan Maria Maria sei Mahusuk Sira = Maria akan tanyakan mereka

- Mak + sala + k = Maksalak

Contoh kata awalan dan akhiran sebagai berikut:

Nian sala tiha ona = Dia sudah salah

Nian Maksalak hela = Dia orang bersalah

4. Aturan kalimat sisipan (infiks)

Gabungan kata awal, tengah, dan akhir untuk membentuk kata baru yang beda arti dengan kata yang pertama. Contohnya sebagai berikut:

- Babadók $=\mathrm{Ba}+$ dók $=$ badók

Contoh kalimat sisipan (infiks) sebagai berikut:

Babadók = Badók dan sisipan Ba, contoh sebagai berikut:

Hau sei badók husi fatin ne'e = Saya akan pergi jauh dari tempat ini

Maria nia baku hela Babadók = Maria sedang menabuh drum

- Aitahan = ta + han = aihan

Contoh kalimat sisipan (infiks) sebagai berikut:

Aitahan = Aihan dan sisipan Ta, contoh sebagai berikut:

Labarik foti tiha Aitahan ne'e = Anak ambilkan daun ini

Ita sempre persija Aihan $=$ Kita selalu membutuhkan makanan

Dalam kata bahasa Tetun untuk kata yang digunakan sebagai kata sisipan (infiks) hanya berapa kata saja.

5. Aturan reduplikasi

Aturan reduplikasi ada dua yaitu reduplikasi sama arti dan reduplikasi beda arti sebagai berikut:

a. Reduplikasi sama arti

- Boot-boot

Boot $=$ besar

Boot-boot $=$ besar-besar

- Funan-funan

Funan $=$ bunga
Funan-funan = bunga-bunga

- Barak-barak

Barak = banyak

Barak-barak = banyak-banyak

- Idak-idak

Idak = satu

Idak-idak = satu-satu

- Livru-livru

Livru = buku

Livru-livru = buku-buku

b. Reduplikasi beda arti

- Hotu-hotu

Hotu = habis

Hotu-hotu = semuanya

- Fila-fila

Fila $=$ balik

Fila-fila = berkali kali

- Oin-oin

Oin $=$ muka

Oin-oin = bermacam-macam

- Ikus-ikus

Ikus = belakang

Ikus-ikus = akhir-akhir

- Liu-liu

Liu = lewat

Liu-liu = diutamakan

6. Aturan kalimat pihak ketiga

Kalimat ini digunakan untuk kata ke ketiga pihak atau juga bisa menunjukkan banyaknya barang.

- Tauk

Tauk $=$ takut

Hatauk = menakutkan saya

Natauk $=$ menakutkan kita

Ratauk = menakutkan mereka

- Dook

Dook $=$ jauh

Hadook = jauhkan saya

Nadook $=$ jauhkan dari dia

Radook $=$ jauhkan dari mereka

- Han

Han = makan

Hahan = saya makan

Nahan $=$ dia makan

Rahan $=$ mereka makan

- Falun

Falun $=$ bungkus

Hafalun = saya bungkus

Nafalun $=$ dia bungkus

Rafalun $=$ mereka bungkus

- Toba

Toba $=$ tidur

Hatoba = ditidurkan

Natoba $=$ dia tidur

Ratoba $=$ mereka tidur 


\section{DESAIN SISTEM}

Bahan utama penelitian ini adalah kata-kata dari bahasa Tetun murni. Sistem ini membutuhkan daftar kata dasar yang dimasukkan dalam kamus kata. Kamus kata dasar berguna untuk mengetahui apakah kata yang dimasukkan dalam sistem sudah merupakan kata dasar atau belum dan untuk menentukan apakah hasil stemming berhasil atau tidak. Jumlah kata dasar yang dipakai dalam kamus kata adalah 176 kata. Kata dasar tersebut diperoleh dari pakar bahasa Tetun Timor Leste. Lalu kata-kata yang diberi imbuhan untuk diuji berjumlah 211.

Peneliti menekankan bahwa dalam hampir semua katakata bahasa Tetun yang terbentuk dari kata dasar dan imbuhan hanya mengandung kata dasar utuh. Tidak ada kata dasar yang mengalami perubahan bentuk saat diberi imbuhan.

Sebelum melalui tahap stemming, data teks harus melewati proses pre-processing. Tahap pre-processing terdiri dari tahap filterisasi dan tahap tokenisasi.

Tahap filterisasi bertujuan untuk menghilangkan tanda baca, angka, dan kata yang tidak penting (tidak bisa diberi awalan, akhiran, dan konfiks) seperti pada Gambar 1.

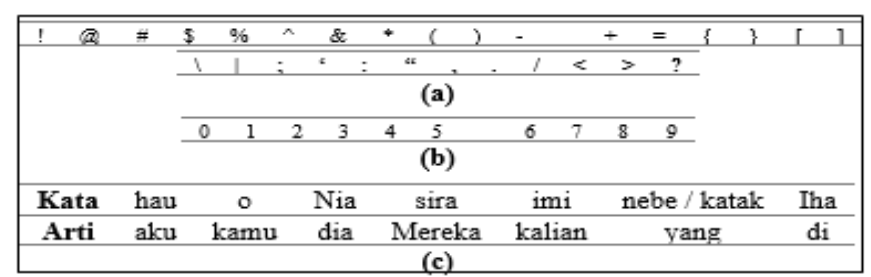

Gambar 1. Filterisasi : (a) Tanda Baca (b) Angka (c) Kata

Tahap pertama dalam proses stemming bahasa Tetun adalah mencari imbuhan awalan pada suatu kata hasil dari tokenisasi. Setiap kata akan dicari sub kata yang sesuai dengan daftar imbuhan awalan. Jika telah ditemukan maka akan dihapus dari kata tersebut untuk membentuk kata dasar. Daftar imbuhan awalan dalam bahasa Tetun seperti pada Tabel 1.

Tabel 1. Daftar Imbuhan Awalan

\begin{tabular}{llll} 
Imbuhan & Contoh Kata & Kata Dasar & Terjemahan \\
\hline ha- & habalun & balun & separuh \\
\hline na- & nabadak & badak & pendek \\
\hline nak- & nakbelit & belit & lengket \\
\hline nam- & namkaer & kaer & memegang \\
\hline
\end{tabular}

Tahap selanjutnya dalam proses stemming bahasa Tetun adalah mencari imbuhan akhiran pada suatu kata hasil dari tokenisasi. Setiap kata akan dicari sub kata yang sesuai dengan daftar imbuhan akhiran. Jika telah ditemukan maka akan dihapus dari kata tersebut untuk membentuk kata dasar. Daftar imbuhan akhiran dalam bahasa Tetun seperti pada Tabel 2.

Tabel 2. Daftar Imbuhan Akhiran

\begin{tabular}{llll}
\hline Imbuhan & Contoh Kata & Kata Dasar & Terjemahan \\
\hline -dór & badinasdór & badinas & rajin \\
\hline
\end{tabular}

\begin{tabular}{llll}
\hline$-n$ & tunun & tunu & bakar \\
\hline -tén & naoktén & naok & pencuri \\
\hline
\end{tabular}

Tahap ketiga dalam proses stemming bahasa Tetun adalah mencari imbuhan awalan sekaligus imbuhan akhiran pada suatu kata. Setiap kata akan dicari sub kata yang sesuai dengan daftar imbuhan awalan dan imbuhan akhiran. Jika telah ditemukan maka akan dihapus dari kata tersebut untuk membentuk kata dasar. Daftar imbuhan awalan dan akhiran dalam bahasa Tetun seperti pada Tabel 3 .

Tabel 3. Daftar Imbuhan Awalan dan Akhiran

\begin{tabular}{ccccl}
\multicolumn{2}{c}{ Imbuhan } & $\begin{array}{c}\text { Contoh } \\
\text { Kata }\end{array}$ & $\begin{array}{c}\text { Kata } \\
\text { Dasar }\end{array}$ & Terjemahan \\
\cline { 1 - 3 } $\begin{array}{c}\text { Awal } \\
\text { an }\end{array}$ & $\begin{array}{c}\text { Akhir } \\
\text { an }\end{array}$ & dalimanuluk & lima & $\begin{array}{l}\text { kelima } \\
\text { puluh, lima }\end{array}$ \\
\hline da- & -nuluk & datoluk & tolu & ketiga, tiga \\
\hline da- & $-\mathrm{k}$ & mahalok & halo & $\begin{array}{l}\text { membuatkan, } \\
\text { buat }\end{array}$ \\
\hline ma- & $-\mathrm{k}$ & maksalak & sala & $\begin{array}{l}\text { bersalah, } \\
\text { salah }\end{array}$ \\
\hline mak- & $-\mathrm{k}$ & & & \\
\hline
\end{tabular}

Tahap selanjutnya dalam proses stemming bahasa Tetun adalah mencari kata sisipan pada suatu kata. Setiap kata akan dicari sub kata yang sesuai dengan daftar imbuhan sisipan. Jika telah ditemukan maka akan dihapus dari kata tersebut untuk membentuk kata dasar. Tabel 4.

Tabel 4. Daftar Imbuhan Sisipan

\begin{tabular}{llll} 
Imbuhan & Contoh Kata & Kata Dasar & Terjemahan \\
\hline -ba- & babadók & badók & drum dan pergi jauh \\
\hline -ta- & aitahan & aihan & daun dan makanan \\
\hline -k- & hakmaten & hamaten & berdiam dimatikan \\
\hline
\end{tabular}

Tahap selanjutnya dalam proses stemming bahasa Tetun adalah jika ada tanda hubung "-" di antara dua kata yang saling bertempelan tanpa spasi maka dianggap sebagai kata reduplikasi. Kata reduplikasi dalam bahasa Tetun tidak ada yang mengalami pergantian huruf vokal di salah satu dari dua kata reduplikasi. Contoh daftar kata reduplikasi bahasa Tetun seperti pada Tabel 5 .

Tabel 5. Contoh Kata Reduplikasi

\begin{tabular}{lll}
\hline Reduplikasi & Kata Dasar & \multicolumn{1}{c}{ Terjemahan } \\
\hline barak-barak & barak & banyak-banyak \\
\hline bikan-bikan & bikan & piring-piring \\
\hline fila-fila & fila & berkali-kali, kembali \\
\hline foun-foun & foun & baru-baru, baru \\
\hline
\end{tabular}

Algoritma stemmer untuk mencari kata dasar bahasa Tetun adalah sebegai berikut :

1. Tahap pertama memasukan kumpulan teks bahasa Tetun.

2. Tahap filtering untuk menghapus semua tanda baca dan huruf yang tidak penting.

3. Tahap tokenisasi untuk memisah teks menjadi bentuk kata-kata.

4. Proses stemming 
a. Tahap pertama dalam proses stemming adalah memeriksa apakah variabel kata ada yang cocok dengan kata dasar dalam kamus. Jika variabel kata cocok dengan daftar kata dasar di kamus maka variabel kata ditampilkan tanpa melewati proses stemming.

b. Tahap kedua dalam proses stemming adalah memeriksa apakah ada konfiks (gabungan imbuhan awalan/prefiks dan akhiran/sufiks). Jika pada variabel kata terdeteksi adanya konfiks maka lanjut ke tahap 4.b.i. Namun jika tidak terdeteksi adanya konfiks maka lanjut ke tahap 4.c.

i. Hapus imbuhan awalan (prefiks) "mak-“, "da-“, "ma-".

ii. Lalu hapus imbuhan akhiran (sufiks) "-nuluk", “k", dan

iii. Menuju ke tahap 5.

c. Tahap ketiga adalah memeriksa apakah ada gabungan imbuhan awalan dan akhiran yang dilarang.

i. Jika ada imbuhan awalan dan akhiran yang dilarang maka periksa apakah ada konfiks. Jika ada maka dilanjutkan ke tahap 4.b.i.

ii. Namun jika konfiks tidak ditemukan maka periksa apakah ada gabungan imbuhan awalan dan akhiran yang dilarang.

1. Jika ada gabungan imbuhan awalan dan akhiran yang dilarang maka periksa apakah ada imbuan akhiran (sufiks) "-dór" dengan disertai suku kata "ha-" di awal variabel kata.

- Jika ada maka hapus imbuan akhiran (sufiks)“-dór”. Lalu menuju ke tahap 5.

- Jika tidak ada ) maka hapus imbuhan awalan (prefiks) "nak-", "nam-“", "ha-“, "na-“. Lalu menuju ke tahap 5.

2. Jika tidak ada gabungan imbuhan awalan dan akhiran yang dilarang maka hapus imbuhan akhiran (sufiks) "-dór", “-n”, "tén”. Lalu menuju ke tahap 5.

d. Jika tidak ada imbuhan awalan dan akhiran yang dilarang maka periksa apakah ada sisipan (infiks).

i. Jika ada sisipan (infiks) maka hapus sisipan tersebut. Lalu menuju ke tahap 5.

ii. Jika tidak ada sisipan (infiks) maka hapus imbuhan awalan (prefiks) "nak-", "nam-“, "ha-“, "na-“. Kemudian dilanjutkan dengan menghapus imbuhan akhiran (sufiks) "-dór", “-n”, "tén”. Lalu menuju ke tahap 5.

Tahap selanjutnya adalah memeriksa apakah variabel kata dasar hasil stemming ada yang cocok dengan kata dasar dalam kamus. Jika ada yang cocok, maka kata hasil stemming ditampilkan dengan status "cocok". Namun jika tidak ada yang cocok, maka hasil stemming ditampilkan dengan status "tidak ada di kamus". Uji coba yang dilakukan terdiri dari stemming imbuhan awalan, akhiran, konfiks, dan infiks. Setiap uji coba diberikan maksimal lima contoh kata. Isi pada kolom Hasil Stemming merupakan hasil stemming disertai dengan poin tahap proses stemming seperti algoritma stemming bahasa Tetun yang telah dijelaskan. Pengumpulan data diperoleh dari artikel, surat kabar, atau majalah yang bertemakan tentang pendidikan dalam bahasa Tetun. Penggunaan bahasa Tetun akan disesuaikan dengan kamus bahasa Tetun seperti Luís Costa Língua Tétum contributors para uma gramática. dan ahli yang akan menvalidasi penelitian ini adalah Lúis Costa [14].

1. Eliminasi Imbuhan Awalan

Eliminasi awalan "ha-"

Tabel 6. Uji Coba Eliminasi Awalan "ha-"

\begin{tabular}{lll}
\multicolumn{1}{c}{ Kata } & Awalan & \multicolumn{1}{c}{ Hasil Stemming } \\
\hline habokon & ha & $\begin{array}{l}\text { [Poin 4.c.i.1.b] => bokon } \\
\text { (Cocok) }\end{array}$ \\
\hline habaruk & ha & [Poin 4.d.ii] $=>$ baruk (Cocok) \\
\hline habeik & ha & [Poin 4.d.ii] $=>$ beik (Cocok) \\
\hline habelit & ha & [Poin 4.d.ii] $=>$ belit (Cocok) \\
\hline hafaluk & ha & [Poin 4.d.ii] $=>$ faluk (Cocok)
\end{tabular}

2. Eliminasi Imbuhan Akhiran

Eliminasi akhiran "-dór"

Tabel 7. Uji Coba Eliminasi Akhiran "-dór"

\begin{tabular}{lll}
\hline \multicolumn{1}{c}{ Kata } & Awalan & \multicolumn{1}{c}{ Hasil Stemming } \\
\hline Hemudór & Dór & $\begin{array}{l}\text { [Poin 4.d.ii] => badinas } \\
\text { (Cocok) }\end{array}$ \\
\hline Devedór & Dór & [Poin 4.d.ii] => deve (Cocok) \\
\hline Fumadór & Dór & $\begin{array}{l}\text { [Poin 4.d.ii] => fuma } \\
\text { (Cocok) }\end{array}$ \\
\hline Hamnasadór & Dór & $\begin{array}{l}\text { [Poin 4.c.i.1.a] => hamnasa } \\
\text { (Cocok) }\end{array}$ \\
\hline Pescadór & dór & $\begin{array}{l}\text { [Poin 4.d.ii] => pesca } \\
\text { (Cocok) }\end{array}$ \\
\hline
\end{tabular}

3. Eliminasi infiks "-ka-"

Tabel 8. Uji Coba Eliminasi Infiks "-k-"

Kata Awalan Hasil Stemming

Hakmate K [Poin 4.d.i] $=>$ hamate (Cocok)

Contoh proses stemming "habaruk" dengan awalan "ha-": a. Periksa kata "habaru" apakah cocok dengan kata pada kamus. Hasilnya adalah tidak ada. Maka lanjut ke tahap b.

b. Periksa kata "habaruk" apakah ada konfiks (gabungan imbuhan awalan (prefiks) dan akhiran (sufiks)) berdasarkan data pada Tabel 3.3. Hasilnya adalah tidak ada. Maka lanjut ke tahap c.

c. Tahap ketiga adalah memeriksa apakah ada gabungan imbuhan awalan (prefiks) dan akhiran (sufiks) yang dilarang. Hasilnya adalah tidak ada. Maka periksa apakah ada sisipan (infiks).

i. Hasilnya adalah tidak ada sisipan (infiks) maka hapus imbuhan awalan (prefiks) "nak-", "nam-“, "ha-“, "na". Kemudian dilanjutkan dengan menghapus imbuhan akhiran (sufiks) “-dór”, “-n”, “tén”. Hasilnya adalah "baruk"

ii. Lalu menuju ke tahap d. 
d. Periksa apakah daftar kata dasar pada kamus ada yang cocok dengan kata "baruk". Hasilnya adalah cocok. Maka tampilkan kata "baruk", status cocok, dan poin "4.d.ii"

Contoh proses stemming "dalimanuluk" dengan awalan "da-"dan akhiran "-nuluk":

a. Periksa kata "dalimanuluk" apakah cocok dengan kata pada kamus. Hasilnya adalah tidak ada. Maka lanjut ke tahap b.

b. Periksa kata "dalimanuluk" apakah ada konfiks (gabungan imbuhan awalan/prefiks dan akhiran/sufiks) berdasarkan data pada Tabel 3.3. Hasilnya adalah ada. Maka lakukan proses berikut :

i. Hapus imbuhan awalan (prefiks) "mak-", "da-", "ma-". Hasilnya adalah "limanuluk".

ii. Lalu hapus imbuhan akhiran (sufiks) "-nuluk", “-k". Hasilnya adalah "lima". (Poin 4.b.ii)

iii. Menuju ke tahap c.

c. Periksa apakah daftar kata dasar pada kamus ada yang cocok dengan kata"lima". Hasilnya adalah cocok. Maka tampilkan kata "lima", status cocok, dan poin "4.b.ii"

Uji coba dilakukan dengan data kamus kata dasar berjumlah 176. Sedangkan jumlah kata yang diuji berjumlah 211. Perhitungan akurasi menggunakan persamaan (1).

$$
\text { Akurasi }=\left(\frac{\sum K D}{\sum K}\right) \times 100 \%
$$

Dimana $\sum K D$ adalah jumlah kata dasar yang berhasil melalui proses stemming, dan $\sum K$ adalah jumlah kata yang melalui uji stemming. Akurasi dinyatakan dalam bentuk persentase (\%). Jumlah stemming benar/cocok 191, jumlah stemming salah/tidak cocok 20, akurasi $90.52 \%$, dan rata-rata waktu stemming semua kata adalah 0.0182 milidetik. Berdasarkan perhitungan menggunakan persamaan (1) maka didapat akurasi sebesar $90.52 \%$. Penyebab kegagalan pada uji coba adalah karena ada kasus spelling exception dan kasus overstemming. Spelling exception adalah kasus dimana kata dasar masih memiliki imbuhan setelah melewati proses stemming. Sedangkan overstemming adalah kasus dimana kata dasar mengalami pengurangan huruf atau suku kata yang dianggap sebagai imbuhan akibat dari proses stemming.

Contoh kasus spelling exception seperti proses stemming awalan "ha-" pada kata "hatanis" menjadi "hanis" padahal yang benar adalah "tanis". Awalan "ha-" masih tetap ada, sedangkan ada huruf atau suku kata (bagian kata dasar) yang terhapus. Penyebab kegagalan adalah karena ada bagian huruf yang dianggap sebagai sisipan ("-ta-") yang dihapus, sedangkan awalan "ha-" diabaikan oleh algoritma.

Contoh kasus overstemming seperti proses stemming awalan "na-" pada kata "nafatin" menjadi "fati" padahal yang benar adalah "fatin". Yaitu ada awalan "na-" sudah berhasil terhapus bersama kasus terhapusnya sebagian huruf dari kata dasar. Penyebab kegagalan adalah karena ada bagian huruf yang dianggap sebagai akhiran "-n" yang dihapus, dan ada bagian huruf yang dianggap sebagai awalan.

\section{KESIMPULAN}

Berdasarkan uraian penjelasan di atas, maka dapat diambil kesimpulan bahwa algoritma stemming bahasa Tetun memiliki tahap utama memeriksa konfiks, gabungan awalan $\&$ akhiran yang dilarang, dan sisipan secara urut. Kegagalan algoritma stemming bahasa Tetun disebabkan karena kesalahan overstemming. Algoritma stemming bahasa Tetun mendapatkan akurasi sebesar $90.52 \%$.

\section{REFERENSI}

[1] Costa, L. (2015). Língua Tétum - contributos para uma gramática, Edições Colibri. Lisboa.

[2] Adriani, M., Asian, J. \& Nazief, B. (2007). Stemming Indonesian: A Confi x-Stripping Approach. ACM Transactions on Asian Language Information Processing, Vol. 6, No. 4, Article 13. 1-13.33.

[3] Thangarasu, M \& Manavalan, R (2013). A Literature Review: Stemming Algorithms for Indian Languages. Jurusan Ilmu Komputer dan Aplikasi Universitas Seni Rupa dan Sains KSRangasamy. 